\title{
Genomic abnormalities affecting mussels (Mytilus edulis- galloprovincialis) in France are related to ongoing neoplastic processes, evidenced by dual flow cytometry and cell monolayer analyses
}

\author{
Benabdelmouna Abdellah ${ }^{1,}{ }^{*}$, Saunier Alice ${ }^{1}$, Ledu Christophe ${ }^{1}$, Travers Marie-Agnes ${ }^{1}$, \\ Morga Benjamin ${ }^{1}$
}

${ }^{1}$ IFREMER, PDG-RBE-SGMM-LGPMM, Station de La Tremblade, Avenue de Mus de Loup, F-17390 La Tremblade, France

* Corresponding author : Abdellah Benabdelmouna, email address : Abdellah.Benabdelmouna@ifremer.fr

\begin{abstract}
:
In the context of the abnormal mass mortality of mussels in France since 2014, Flow CytoMetry (FCM) was used in 2015 and 2016 to study the DNA content and cell cycle characteristics of hemic circulating cells collected from 2000 mussels. The mussels were sampled from 12 wild and cultivated blue mussels stocks distributed along the French Atlantic coast from the south Brittany to Pertuis Charentais areas. During these surveys, various genetic abnormalities were frequently detected, and ploidy characteristics revealed contrasting profiles that corresponded to respective contrasting sanitary status, i.e. healthy mussels with high cytogenetic quality (HCQ) versus diseased mussels with low cytogenetic quality (LCQ). In the present work, FCM and hemocytology cell monolayer techniques were combined in order to determine the putative causes of the observed genetic abnormalities that were significantly associated with mortality levels. FCM and cell monolayer approaches permitted the definition of new threshold values delimiting HCQ mussels from LCQ ones. FCM histograms of mussels from the HCQ group showed one single or a largely dominant population of diploid (2n) nuclei and a large majority of normal hemocytes. Hemolymph cell-monolayer analyses showed predominantly acidophil granulocytes characterized by nuclei of normal size and a large cytoplasm with numerous granulations. In contrast, FCM histograms for the LCQ group showed, in addition to the normal diploid (2n) nuclei, populations of nuclei that displayed aneuploidy patterns in a broad ploidy range, including diploid-triploid (2-3n), tetraploid-pentaploid $(4-5 n)$ and heptaploid-octaploid levels (7-8n). The corresponding hemolymph cell-monolayer showed cellular features characteristic of disseminated neoplasia disease with frequent abnormal anaplastic cells that exhibited noticeable numbers of mitotic figures with both normal and aberrant chromosomes segregation patterns. These neoplastic cells were a rounded shape with a reduced, granulation-free cytoplasm and large $(11-12 \mu \mathrm{m}$ ) to very large (up to $21 \mu \mathrm{m}$ ) round or ovoid nuclei that correspond to the $4-5 n$ and $7-8 n$ nuclei previously detected by FCM analyses. These characteristics suggest that the genetic abnormalities detected by means of FCM were related to an ongoing neoplastic process that is affecting blue mussels in France, at least since the onset in 2014 of
\end{abstract}


the mortality that heavily impacted French blue mussels stocks

\section{Graphical abstract}

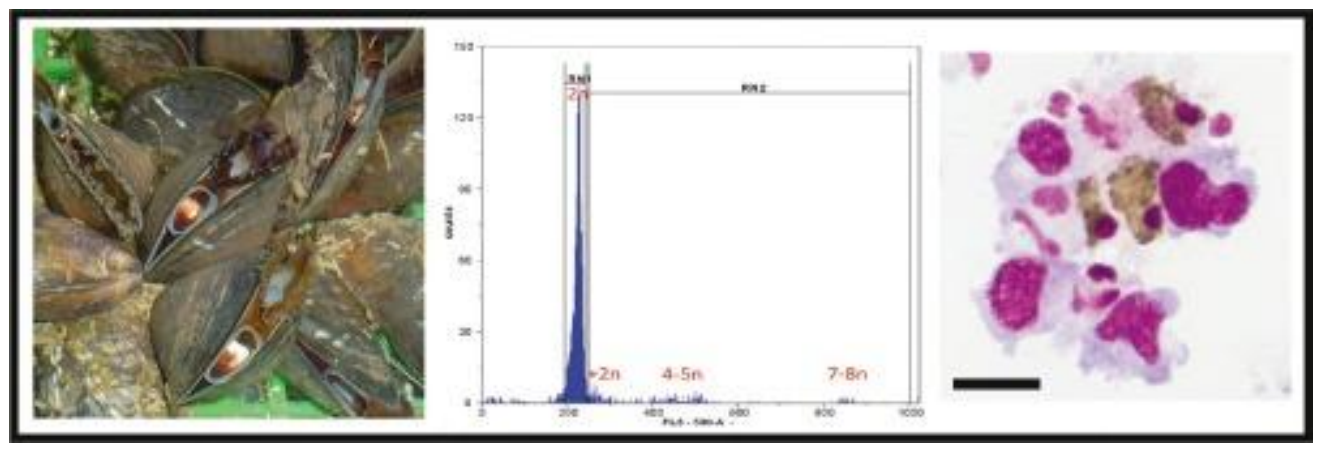

\section{Highlights}

- Percentages of non-diploid nuclei in mussel hemolymph could vary from $2 \%$ to $25 \%$. FCM analysis constituted two contrasted groups that were further characterized by cell monolayer approach. - New threshold values to qualify the cytogenetic quality of mussels were established. Hemocytes of animals with low cytogenetic quality presented enlarged nuclei and mitotic figures. We propose that the genomic abnormalities are related to ongoing neoplastic process.

Keywords : Mussels, Hemocytes, Flow cytometery, Hemocytology, Cytogenetic quality, Neoplasia 


\section{Introduction}

In France, farming of Mytilus spp. consisting of the blue mussel Mytilus edulis, the Mediterranean mussel $M$. galloprovincialis and hybrids of both species is an important industry with production varying during the last decade from 71,000 to 79,000 metric tons per year (FAO, 2014). However, the production of French mussels has decreased dramatically since 2014 because of sudden and unfamiliar mass mortality (90-100\%) of both juvenile and adult mussels cultivated at various French Atlantic areas, including south and north Brittany, Bourgneuf Bay and Charentais Sound (Béchemin et al., 2015). Mortality of both naturally occurring and cultured blue mussels has been reported in many other locations around the world (Tremblay et al., 1998; Myrand et al., 2000; Fuentes et al., 2002). The extent of mortality can be highly variable and several stress-related factors have been investigated, including pathogens, pollution, temperature, food depletion and reproduction, leading to a preliminary conclusion that none of these factors alone can explain the cause. Although blue mussels are generally considered to be resilient to environmental disturbances and pollutants; several studies have shown that the exposure of mussels to environmental contaminants results in DNA damage. Damage includes abnormalities in DNA content and structure, as well as the progressive development of circulating aneuploid-polyploid cells in the hemolymph, in particular the development of a fatal leukemia-like cancer disease called hemic (or disseminated) neoplasia (Elston et al., 1992; Bihari et al., 2003; Vassilenko and Baldwin 2014). This malignant disease has been reported in 15 species of marine bivalves with a world-wide distribution that includes the cockle Cerastoderma edule, four species of oysters, six species of clams and five species of mussels (Farley et al., 1986; Elston et al., 1992; Villalba et al., 1995; Villalba et al., 2001; da Silva et al., 2005; Delaporte et al., 2008; Galimany and Sunila 2008; Le Grand et al., 2010; Diaz et al., 2011). The disease is characterized by proliferation of anaplastic circulating cells with enlarged and pleiomorphic 
nuclei, a high nucleus-to-cytoplasm ratio and frequent presence of mitotic figures (Elston et al., 1992). In late stages, anaplastic cells completely replace normal hemocytes and penetrate various tissues such as connective tissue, gonads, the mantle and foot (Barber 2004; Carballal et al., 2015). This disease is progressive and commonly fatal causing significant mortality and decrease in market harvests of economically important species (Bower 1989; Elston et al., 1992; Barber 2004, Carballal et al., 2015).

In the context of the abnormal outbreaks of mass mortality of blue mussels in France since 2014, it was hypothesized that mortality was probably linked to poor cytogenetic quality, particularly in terms of ploidy variations and cell cycle DNA alterations affecting circulating cells in the hemolymph. These genetic abnormalities can be reliably studied by Flow CytoMetry (FCM) methods (Elston et al., 1990; Moore et al., 1991; Reno et al., 1994; Da Silva et al., 2005, Vassilenko and Baldwin 2014). FCM was used in a previous study to investigate the DNA content and cell cycle characteristics of hemic cells collected from various wild and cultivated mussels stocks that had, at our best knowledge, no history of mortality before 2014 and that showed much higher mortality levels after that time (Benabdelmouna and Ledu 2016). In that survey, different thresholds of genetic abnormality (GA\%) were established and appeared to be highly predictive of the final mortality levels. Interestingly, ploidy characteristics of hemic cells revealed contrasting profiles, which corresponded to respective contrasting sanitary status, apparently healthy $v s$ diseased mussels. Normal healthy mussels were shown to be of high cytogenetic quality (HCQ) and contained nearly entirely diploid cells in their hemolymph while abnormal diseased mussels had low cytogenetic quality (LCQ) and contained, in addition to normal diploid cells, a broad continuum of aneuploid-polyploid cells that could either be linked to genotoxic effects of unknown origin and/or most probably to ongoing hemic neoplasia disease. 
From the Benabdelmouna and Ledu (2016) study, it was apparent that systematically

111 combining FCM and light microscopy methods (especially hemocytology by cell monolayer

112 technique) would be beneficial in order to $i$ ) determine the putative cause of the observed

113 genetic abnormalities, ii) to characterize at the cellular level the disorder during mussel

114 mortality events, and iii) determine more precise thresholds of genomic abnormality (GA\%)

115 that could provide tools to manage mortality outbreaks. For this purpose, non-invasive FCM

116 analyses were used to preliminarily constitute two groups of blue mussels of cytogenetic

117 quality LCQ and HCQ. Individual mussels were then subjected to hemocytology exams by

118 the cell monolayer technique ("cytospin®”) in order to establish a clear relationship between

119 FCM-based cytogenetic quality status and the corresponding cellular and cytological 120 characteristics of hemocytes. 


\section{$\underline{\text { Material and Methods }}$}

123

124

125

126

127

128

129

130

131

132

133

134

135

\section{Biological material}

Adult mussels used in this study were randomly collected during April 2017 from a wooden pole "bouchot" grow-out facility dedicated to mussel culture and located along the English Channel at Donville les Bains in western Normandy, France (48'52'957N; 00'34'892W). Farmer's mussel seed were originally collected during spring 2016 from natural spatfall at Fouras in the Pertuis Charentais area of the Atlantic coast. At the end of Summer 2016, mussel spat of less than $1 \mathrm{~mm}$ shell length that settled on coconut fiber ropes at a mean density of 10,000 individuals per meter were transferred to their final growing zone at Donville les Bains. In April 2017, following a brief mortality event of about 15\%, 300 live adult mussels of $3-6 \mathrm{~cm}$ shell length were transported to our LGPMM experimental hatchery at LaTremblade where they were maintained in a separate tank alimented through 250 -L per hour of unheated and UV-filtered seawater

\section{Hemolymph collection}

Mussels were anaesthetized in a solution containing $50 \mathrm{~g} \mathrm{~L}^{-1}$ of magnesium chloride until the valves opened. Hemolymph was withdrawn in a non-destructive manner from the adductor muscle of each individual mussel with sterile $1 \mathrm{~mL}$ syringe fitted with a 26 gauge needle. For each animal, a volume of approximately $0.2 \mathrm{~mL}$ of hemolymph was collected and stored for less than $5 \mathrm{~min}$ in an Eppendorf microcentrifuge tube on ice to prevent clumping. Each hemolymph sample was immediately subjected to FCM and cell monlayer analyses. 
FCM analyses were conducted as described in Benabdelmouna and Ledu (2016). In

brief, $0.1 \mathrm{~mL}$ of hemoplymph collected from each individual mussel was used for nuclei extraction and staining. The samples were first collected in a $1.5 \mathrm{~mL}$ Eppendorf tube containing $1 \mathrm{~mL}$ of nuclei extraction buffer $\left(5 \mathrm{mM} \mathrm{MgCl}_{2}, 85 \mathrm{mM} \mathrm{NaCl}, 10 \mathrm{mM}\right.$ Tris, $0.1 \%$ Triton $\mathrm{X}-100, \mathrm{pH} 7$ ) and the nuclei were then collected by filtration through a $30-\mu \mathrm{m}$ nylon sieve. Samples were simultaneously treated with DNase-free RNase A $\left(50 \mu \mathrm{g} \mathrm{mL}{ }^{-1}\right.$, Sigma, R4875, Saint-Louis, MI, US) and stained at room temperature for $30 \mathrm{~min}$ in the dark with propidium iodide (PI, Sigma, P4170, Saint-Louis, MI, US) at a concentration of $50 \mu \mathrm{g} \mathrm{mL}-1$ in a 2-mL final solution. FCM was performed on a Partec PA II flow cytometer equipped with a 590 nm, 30 mW green laser (Sysmex, Sainte Geneviève des Bois, France). Peak position and cell-cycle estimates were done as described in Benabdelmouna and Ledu (2016).In order to distinguish nuclei in the $\mathrm{G} 2 / \mathrm{M}$ phase from doublets of $\mathrm{G} 0 / \mathrm{G} 1$ nuclei that have the same DNA content, FL3-area vs FL3-width dot-plots were used to gate single nuclei. Thus a region (R1) was drawn on these dot-plot representations to discriminate single nuclei from doublets. After gating them on R1, single nuclei were next plotted on a FL3-area histogram on 1024 linear scale and used to calculate the percentages of nuclei populations according to their DNA content. Selection of the two mussel groups according to their cytogenetic quality status (LCQ vs HCQ) was done according to our previous work (Benabdelmouna and Ledu 2016) that fixed an upper limit of $10 \%$ of non-diploid nuclei for a normal HCQ mussel. Beyond this limit, mussels were considered abnormal with a LCQ status.

\section{Cell monolayer analysis}

Hemocytological analyses by cell monolayer technique were conducted for individuals with contrasting FCM profiles constituting the LCQ and HCQ groups. For each of these 
selected mussels, $40 \mu \mathrm{L}$ of freshly collected hemolymph taken from the venous sinuses in the adductor muscle were pipette onto a poly-L-lysine coated glass slides for cyto-centrifugation $\left(4^{\circ} \mathrm{C}, 1 \mathrm{~min}, 500 \mathrm{rpm}\right.$ - Universal 16R, Hettich-Zentrifugen, Tuttlingen, Germany). Supernatant was removed; each slide was dried at room temperature and then stained with hematoxylin-eosin and observed under light microscopy (BX50, Olympus, Tokyo, Japan). Digital images were also captured using a Zeiss Axioplan 2 Imaging microscope, and digitized images were prepared for printing in Axiovision software (Zeiss).

Twenty individuals were analyzed; ten each of HCQ and LCQ condition. A total of 150 cells was counted per sample for three cell types (granulocytes, normal hyalinocytes and mitotic figures) and measured using Stream Essential software (v.1.9.3).

\section{Statistical analysis}

Based on the ploidy level variation, two cytogenetic qualities were defined: HCQ ( $\mathrm{n}=10$ specimens, $\mathrm{n}=150$ cell/specimen) and LCQ ( $\mathrm{n}=10$ specimens, $\mathrm{n}=150$ cell/specimen). Normality of the residuals using the Shapiro test, homoscedasticity using the Bartlett test and then non parametric Wilcoxon test were performed to compare these two groups using $\mathrm{R}$ software (v.1.0.153, RStudio Team, 2015). Plots were performed using ggplot2 package (Wickham, 2009). 
During the week of their reception in the hatchery, 128 mussels of $5 \mathrm{~cm}$ mean shell length randomly collected from "Donville les Bains" were individually analyzed by FCM in order to contrast the two groups, HCQ versus LCQ. FCM analyses permitted the calculation of the respective percentages of non-diploid nuclei $(\%>2 n)$ in the hemolymph from each mussel and the qualification of its cytogenetic status (LCQ versus HCQ). FCM analyses of mussels from this site showed that the percentages of non-diploid nuclei in the hemolymph varied from $2 \%$ to $25 \%$, with a mean value of genetic abnormality (GA\%) of $10 \%$ for this site. Of the 128 analyzed mussels, $68(53.1 \%)$ were determined to have an LCQ status while the remaining mussels $(46.9 \%)$ were of HCQ status. Sixty mussels were then selected to contrast the two groups. The LCQ group contained 40 mussels with the highest percentages of non-diploid nuclei, varying from $10 \%$ to $25 \%$ (average $19.9 \%$ ), while the HCQ group contained 20 mussels with the lowest percentages of non-diploid nuclei, varying from 2 to 5.6\% (average 3.1\%), a statistically significant difference ( $\mathrm{p}<0.001$; Wilcoxon test) (Fig. 1).

To establish a clear relationship between the FCM-based cytogenetic quality status and the correspondent cellular and cytological characteristics of hemocytes collected from individual mussels in the LCQ and HCQ groups, we compared the FCM patterns and their corresponding cytological figures obtained in the cell monolayer approach. FCM histograms of mussels from the HCQ group showed one single or very largely dominant population of diploid (2n) nuclei in the G0/G1 phase (Fig. 2a). Hemolymph cell-monolayers from the HCQ mussels, and more especially those that exhibited less than $5 \%$ of non-diploid nuclei in their hemolymph (Fig. 2b), showed a large majority of normal hemocytes with nucleus stained dark purple and cytoplasm light purple. Typical hemocytes of HCQ mussels were predominantly acidophile granulocytes with high cytoplasm to nucleus ratio and were characterized by nuclei of normal size (mean size of $5.7 \pm 1.2 \mu \mathrm{m}$ ) and large cytoplasms with 
numerous granulations. In addition, some basophile hyalinocytes with low cytoplasm/nucleus ratio were detected with a nucleus of normal size enclosed in a much reduced cytoplasm.

Mussels from the LCQ group presented FCM histograms with more complex patterns, showing, in addition to the normal diploid population of cells, additional populations of cells with non-diploid nuclei displaying aneuploidy patterns, a broad ploidy range including diploid-triploid (2-3n), tetraploid-pentaploid (4-5n, Fig. 3A) and even heptaploid-octaploid levels (7-8n, Fig. 3B). Abnormal cells were observed in the corresponding hemolymph cellmonolayer slides from LCQ mussels; proportions varied similarily to variation of ploidy levels, indicating most probably different disease status in the LCQ group. Compared to normal diploid cells with nuclei of normal mean size (5-6 $\mu \mathrm{m}$ of diameter), the abnormal neoplastic cells were rounded with a reduced, granulation-free cytoplasm and large (11-12 $\mu \mathrm{m}$ ) to very large (up to $20 \mu \mathrm{m}$ ) round or ovoid nuclei that probably correspond to the $4-5 \mathrm{n}$ and 7-8n nuclei previously detected by FCM analyses (Fig. 4). Examination of cell monolayer patterns obtained from the different mussel groups showed the presence of frequent mitotic figures with both normal and aberrant chromosomes segregation patterns (Fig. 4).

Cell monolayer analyses of hemolymph samples from additional HCQ mussels with intermediate percentages of non-diploid nuclei $(6-10 \%)$ also exhibited abnormal cells and mitotic figures but at a lesser extent than in LCQ mussels with $<10 \%$ non-diploid nuclei (not shown).

Based on cell characteristics (cell types, mean size of nuclei and percentage of mitotic figures), examination of ten individuals from each of the LCQ and HCQ mussel groups showed statistical differences for mitotic figures and normal hyalinocytes. While the number of mitotic figures was significantly higher in LCQ than in HCQ specimens (median: $27.2 \mathrm{vs}$ $6.3, \mathrm{p}<0.001$, unilateral Wilcoxon test), the number of normal hyalinocytes was statistically 
237 lower in LCQ than HCQ (median: 41.1 vs 72.9, $\mathrm{p}<0.001$, unilateral Wilcoxon test,). No 238 difference was observed for number of granulocytes between LCQ and HCQ groups (Fig. 239 5A). Finally, whereas the median size of nuclei was $5.7 \pm 1.2 \mu \mathrm{m}$ for HCQ specimens, nuclei 240 of LCQ individuals were significantly larger at $7.5 \pm 2.4 \mu \mathrm{m}(\mathrm{p}<0.001$, unilateral Wilcoxon 241 test, Fig. 5B). 
244 Since 2014, the French Mytilus spp. industry has faced outbreaks of mortality rates of 90$245100 \%$, affecting both juveniles and adults. A previous study reported the presence of genetic 246 abnormalities affecting hemic cells that also showed characteristics suggesting disseminated 247 neoplasia disease (Benabdelmouna and Ledu, 2016). In that study, the extent of these genetic abnormalities was shown to be significantly correlated with mortality levels of blue mussels.

In the present work, flow cytometry analysis and cell monolayer analysis appeared to be efficient and complementary to detect abnormal neoplastic cells. These techniques allowed direct observation of a higher quantity of hemic cells, the primary host cell type affected by the disease. In addition, the cell monolayer technique avoids other cell types and histological structures that hamper observation of abnormal cells.

Hemocytology of LCQ mussels showed morphological characteristics that are consistent with disseminated neoplasia reported in other bivalve species (Barber 2004; Carballal et al., 2015). Specifically, similarities included anaplasia with affected cells presenting an undifferentiated aspect, and proliferative character with abundant mitotic figures present and frequent abnormal chromosomal segregation patterns. Simultaneous use of FCM and cell monolayer techniques showed 6-10\% non-diploid nuclei in HCQ mussels, but with some abnormal cells in their hemolymph, suggesting that these mussels may be in transition to LCQ status. As a consequence, we believe that the threshold value of non-diploid nuclei in the hemolymph should be lowered to 5\% to delimit HCQ mussels from LCQ mussels.

Previous FCM studies reported that mussel neoplastic cells were either $4 \mathrm{n}$ or $5 \mathrm{n}$ (Elston et al., 1990; Moore et al., 1991). In addition to the normal diploid nuclei and to the already described tetraploid-pentaploid (4-5n) neoplastic nuclei, we observed populations of 
nuclei that displayed aneuploidy patterns including diploid-triploid (2-3n) and heptaploidoctaploid levels (7-8n). The corresponding hemolymph cell-monolayer figures showed cellular features that could be directly linked to the various ploidy levels described above. These neoplastic cells were of rounded shape with a reduced, granular-free cytoplasm and large $(11-12 \mu \mathrm{m})$ to very large (up to $21 \mu \mathrm{m}$ ) round or ovoid nuclei. Assuming that a normal diploid nucleus has a mean size of $5.7 \mu \mathrm{m}$, we concluded that $11-12 \mu \mathrm{m}$ nuclei and $21 \mu \mathrm{m}$ nuclei correspond to the aneuploid 4-5n and 7-8n nuclei, respectively, previously detected by FCM analyses. It was apparent that this increase in DNA in circulating neoplastic cells occurred in parallel with the morphological changes described in hemocytological preparations. In bivalve molluscs with disseminated neoplasia, the alterations in ploidy appear to be closely related to alterations in nuclear structure. The fact that nuclear hypertrophy in bivalves results from the polyploidy of neoplastic cells was previously reported in various bivalve molluscs including Mytilus sp. (Moore et al., 1991; Carella et al., 2013, Vassilenko and Baldwin 2014; Carella et al., 2017), Cerastoderma edule (Collins, 1998; da Silva et al., 2005), Limecola balthica (Smolarz et al., 2005) and Mya arenaria (Reno et al., 1994; Delaporte et al., 2008). In these cases, the genetic abnormalities linked to neoplasia comprised various small to large-scale cytogenetic alterations, including principally aneuploidies and whole genome multiplications.

The neoplastic LCQ mussels analyzed exhibited the coexistence of several aneuploid peaks. This phenomenon has been observed in bivalve species affected by mortality outbreaks, including mussels (Elston et al., 1990; Moore et al., 1991) and cockles (Collins, 1998; da Silva et al., 2005; Legrand et al., 2010), and was also found in studies where an increase in ploidy in the neoplastic cell populations is described during the progression of the disease (Elston et al., 1990; Legrand et al., 2010). Based on FCM, Elston et al. (1990) demonstrated that the progressive nature of the disease was evidenced by progressive 
increases in abnormal polyploid cell populations and decreases in the proportion of normal diploid cells. The same authors suggested that cells in the non-diploid peak could correspond to neoplastic cells undergoing mitosis as the ratio between the second and first peaks is often close to 2.0. In cockles, Legrand et al., (2010) proposed two hypotheses to explain this pattern: (1) the presence of two concomitant neoplasia mechanisms developing within a single individual, each mechanism leading to a unique but different ploidy peak, or (2) an altered cell-division mechanism of neoplastic cells undergoing mitosis. Interestingly, in our present work, frequent abnormal mitotic forms were observed showing various abnormal chromosome segregation patterns. This finding supports the second explanation proposed above and we also suggest that abnormal mitosis is an important mechanism in the neoplastic processes affecting the blue mussels. In addition, histopathological examination of diseased mussels revealed many abnormal mitoses, and abnormal multipolar mitoses have been previously described in mussels from various geographical regions (Farley, 1969; Reno et al., 1994; Usheva and Frolova, 2000). As in vertebrates, frequency of abnormal mitoses seems to serve as a distinctive criterion for tumor progression in bivalve molluscs. It is noteworthy that in the present work, mitotic figures were found to be more frequent in LCQ mussels with low percentages of non-diploid nuclei than in LCQ mussels with high percentages of non-diploid nuclei. Sunila (1991) suggested that the level of mitotic activity of neoplastic cells in the hemolymph depended on the stage of neoplasm development. The highest mitotic index values were recorded at the early stages of the hemolymph neoplasia, when less than $10 \%$ of hemocytes in $M$. arenaria are replaced by the neoplastic cells. At the terminal stages, the mitotic index of $M$. arenaria neoplastic cells is much lower (1.2\%) and is similar to that estimated in the heavily diseased mussels that we observed in the present work. Accordingly, we assumed that, above the threshold level of $5 \%$ of non-diploid nuclei, an ongoing neoplastic process occurs with a continuum of cellular modifications and an increase of the ploidy level 
in which impaired mitosis plays an important role. Indeed, impaired mitosis has been shown to negatively affect genome stability by causing whole chromosome aneuploidy and also by promoting the acquisition of potentially tumor-promoting mutations (Ganem and Pellman 2012). Thus, aneuploidies affecting the whole chromosome or only a segment of the chromosome can alter gene copy number of relevant oncogenes and tumor suppressors, at least in part by facilitating loss of heterozygosity of known tumor suppressor genes (Weaver et al., 2007; Baker et al., 2009). A number of cellular defects are known to generate whole chromosome aneuploidy, including atypical mitotic spindle assembly, inefficient chromosome distribution, abnormal microtubule dynamics, supernumerary centrosomes, and a defective spindle assembly checkpoint (Compton, 2011; Gordon et al., 2012; Holland and Cleveland, 2012). All these cellular defects manifest during mitosis when chromosomes physically separate. Thus, it is widely accepted that abnormal mitosis can contribute to tumorigenesis via the generation of aneuploidy.

In several areas of the world, disseminated neoplasia reaches epizootic prevalence in some bivalve species causing serious regional economic damage to the aquaculture industry (Ciocan and Sunila 2005). The high prevalence of mussels affected by high prevalence of genetic abnormalities in relation to an ongoing neoplasic process (this work) and previous association of the same genetic abnormalities with mortality outbreaks in France (Benabdelmouna and Ledu 2016), indicate that this disease could be considered an important morbidity and mortality cause for mussels cultured in France. The techniques used in this work, and most principally FCM, could be powerful tools to help manage current mussel mortality, allowing determination of cytogenetic quality of wild and cultivated mussel beds with the aim of preserving good quality animals and eliminating/reducing individuals of poor quality, and the use of FCM-qualified juveniles as seeds in cultured stocks. 
343 The authors are grateful to J. Normand for help in mussel stock sampling and to the LGPMM 344 hatchery staff for technical assistance in the hatchery. We also thank JF Pepin for critical 345 reading of the manuscript. This work was funded by the French DPMA (Direction des 346 pêchesmaritimeset de l'aquaculture, DPMA-2017-MORBLEU CONVENTION Nº: 347 17/1212952). 
Baker, D.J., Jin, F., Jeganathan, K.B., van Deursen. J.M., 2009. Whole chromosome instability caused by Bub1 insufficiency drives tumorigenesis through tumor suppressor gene loss of heterozygosity. Cancer Cell. 16, 475-486.

Barber, B.J., 2004. Neoplastic diseases of commercially important marine bivalves. Aquat. Living. Resour. 17, 449-466.

Béchemin, C., Soletchnik, P., Polsenaere, P., Le Moine, O., Pernet, F., Protat, M., Fuhrman, M., Quéré, C., Goulitquer, S., Corporeau, C., Lapègue, S., Travers, A., Morga, B., Garrigues, M., Garcia, C., Haffner, P., Dubreuil, C., Faury, N., Baillon, L., Baud, J-P., Renault. T., 2015. Episodes de mortalité massive de moules bleues observés en 2014 dans les Pertuis charentais. Bulletin épidémiologique, santé animale et alimentation, 67, 6-9.

Benabdelmouna, A., Ledu, C., 2016. The mass mortality of blue mussels (Mytilus spp.) from the Atlantic coast of France is associated with heavy genomic abnormalities as evidenced by flow cytometry. J. Invertebr. Pathol. 138, 30-38.

Bihari, N., Micic, M., Batel, R., Zahn, R.K., 2003. Flow cytometric detection of DNA cell cycle alterations in hemocytes of mussels (Mytilus galloprovincialis) off the Adriatic coast. Croatia. Aquat. Toxicol. 64, 121-129.

Bower, S., 1989. The summer mortality syndrome and haemic neoplasia in the blue mussels (Mytilus edulis) from British Columbia.Can. Tech. Rep. Fisheries Aquat. Sci. 1703, 165.

Carballal, M.J., Barber, B.J., Iglesias, D., Villalba, A., 2015. Neoplastic diseases of marine bivalves. J. Invertebr. Pathol. 131, 83-106. 
Carella, F., De Vico, G., Landini, G., 2017. Nuclear morphometry and ploidy of normal and neoplastic haemocytes in mussels. Plos One. 12 (3), e0173219.

Carella, F., Figueras, A., Novoa, B., De Vico, G., 2013. Cytomorphology and PCNA expression pattern in bivalves Mytilus galloprovincialis and Cerastoderma edule with haemic neoplasia. Dis. Aquat. Org. 105, 81-87.

Ciocan, C., Sunila, I., 2005. Disseminated neoplasia in blue mussels, Mytilus galloprovincialis, from the Black Sea, Romania. Mar. Pollut. Bull. 50, 1335-1339.

Collins, C., 1998. Studies on a Neoplasm of the Cockle, Cerastoderma edule (Linnaeus). Ph. D. Thesis Dissertation, National University of Ireland, Cork, pp. 155.

Compton, D.A. 2011. Mechanisms of aneuploidy.Curr.Opin. Cell Biol. 23, 109-113.

da Silva, P.M., Soudant, P., Carballal, M.J., Lambert, C., Villalba, A., 2005. Flow cytometric DNA content analysis of neoplastic cells in haemolymph of the cockle Cerastoderma edule. Dis. Aquat. Organ. 67, 133-139.

Delaporte, M., Synard, S., Pariseau, J., McKenna, P., Tremblay, R., Davidson, J., Berthe, F.C, 2008. Assessment of haemic neoplasia in different soft shell clam Mya arenaria populations from eastern Canada by flow cytometry. J. Iinvert. Pathol. 98,190-197.

Diaz, S., Villalba, A., Insua, A., Soudant, P., Fernandez-Tajes, J., Mendez, J., Carballal, M.J., 2011. Disseminated neoplasia causes changes in ploidy and apoptosis frequency in cockles Cerastoderma edule. J. Invertebr. Pathol. 113, 214-219.

Dixon, D.R., Jones, I.M., Harrison, F.L., 1985. Cytogenic evidence of inducible processes linked with metabolism of a xenobiotic chemical in adult and larval Mytilus edulis. Sci Total Environ. 46, 1-8.

Elston, R.A., Drum, A.S., Allen, S.K., 1990. Progressive development of circulating polyploid cells in Mytilus with hemic neoplasia. Dis. Aquat. Organ. 8, 51-59. 
Elston, R.A., Kent, M.L., Drum, A.S., 1988. Progression, lethality and remission of hemic neoplasia in the bay mussel, Mytilus edulis. Dis. Aquat. Org. 4, 135-142.

Elston, R.A., Moore, J.D., Brooks, K., 1992. Disseminated neoplasia of bivalve molluscs. Rev. Aquat. Sci. 6, 405-466.

FAO, 2014.Fisheries and aquaculture software.FishStatJ - software for fishery statistical time series. FAO Fisheries and Aquaculture Department Rome. http://www.fao.org/fishery/statistics/software/fishstatj/en.

Farley, C.A., 1969. Sarcomatid proliferative disease in a wild population of blue mussels (Mytilus edulis). J. Natl. Cancer Inst. 43 (2), 509-516.

Farley, C.A., Otto, S.V., Reinisch, C.L., 1986. New occurrence of epizootic sarcoma in Chesapeake Bay soft shell clams, Mya arenaria. Fish. B-NOAA 84, 851-857.

Fuentes, J., Lopez, J.L., Mosquera, E., Vazques, J., Villalba, A., Alvarez, G., 2002. Growth, mortality, pathological conditions and protein expression of Mytilus edulis and $M$. galloprovincialis crosses cultured in the Ria de Arousa (NW Spain). Aquaculture 213, 233-251.

Galimany, E., Sunila, I., 2008. Several cases of disseminated neoplasia in mussels Mytilus edulis (L.) in Western Long Island Sound. J. Shellfish Res. 27, 1201-1207.

Ganem, N.J., Pellman, D. 2012. Linking abnormal mitosis to the acquisition of DNA damage. J. Cell. Biol. 6, 871-881.

Gordon, D.J., Resio, B., Pellman. D., 2012.Causes and consequences of aneuploidy in cancer.Nat. Rev. Genet.13, 189-203.

Le Grand, F., Kraffe, E., de Montaudouin, X., Villalba, A., Marty, Y., Soudant, P., 2010. Prevalence, intensity, and aneuploidy patterns of disseminated neoplasia in cockles 
(Cerastoderma edule) from Arcachon bay: seasonal variation and position in sediment. J. Invertebr. Pathol. 104, 110-118.

Lowe, D.M., Moore, M.N., 1978. Cytology and quantitative cytochemistry of a proliferative atypical haemocytic condition in Mytilus edulis. J. Natl. Cancer Inst. 60, 1455-1459.

Moore, J.D., Elston, R.A., Drum, A.S., Wilkinson, M.T., 1991. Alternate pathogenesis of systemic neoplasia in bivalve mollusk Mytilus. J. Invert. Pathol. 58, 231-243.

Myrand, B., Guderley, H., Himmelman, J., 2000. Reproduction and summer mortality of blue mussels Mytilus edulis in the Magdalen Islands, southern Gulf of St. Lawrence. Mar. Ecol. Prog. Ser. 197, 193-207.

Reno, P.W., House, M., Illingworth, E., 1994. Flow cytometric and chromosome analysis of soft-shell clams Mya arenaria with disseminated neoplasia. J. Invertebr. Pathol. 64 (2), $163-172$.

RStudio Team (2015). RStudio: Integrated Development for R. RStudio, Inc., Boston, MA URL http://www.rstudio.com/.

Sequim, W.A., Holland, A.J., Cleveland, D.W., 2012. Losing balance: the origin and impact of aneuploidy in cancer. EMBO Rep. 13, 501-514.

Smolarz, K., Thiriot-Quievreux, C., Wolowicz, M., 2005. Recent trends in the prevalence of neoplasia in the Baltic clam Macoma balthica (L.) from the Gulf of Gdańsk (Baltic Sea). Oceanologia 47 (1), 61-74.

Sunila, I., 1991. Respiration of sarcoma cells from the soft-shell clam Mya arenaria L. under various conditions. J. Exp. Mar. Biol. Ecol. 150 (1), 19-29.

Tremblay, R., Myrand, B., Sevigny, J.M., Guderley, H., 1998. Bioenergetic and genetic parameters in relation to susceptibility of blue mussels, Mytilus edulis (L.) to summer mortality. J. Exp. Mar. Biol. Ecol. 221, 27-58. 
Usheva, L.N., Frolova, L.T., 2000. Neoplasia in the connective tissue of the mussel Mytilus trossulus from polluted areas of Nakhodka Bay in the Sea of Japan. Russ. J. Dev. Biol. $31(1), 63-70$.

Vassilenko, E., Baldwin, S. A., 2014. Using flow cytometry to detect haemic neoplasia in mussels (Mytilus trossulus) from the Pacific Coast of Southern British Columbia, Canada. J. Invert. Pathol. 117, 68-72.

Villalba, A., Carballal, M.J., Lopez, C., 2001. Disseminated neoplasia and large foci indicating heavy haemocytic infiltration in cockles Cerastoderma edule from Galicia (NW Spain). Dis. Aquat. Organ. 46, 213-216.

Villalba, A., Peters, E.C., Lopez, M.C., Caraballal, M.J., 1995. Disseminated sarcoma in the clam Ruditapes decussatus in Galicia (NW Spain). J. Invert. Pathol. 65, 76-78.

Weaver, B.A.A., Silk, A.D., Montagna, C., Verdier-Pinard, P., Cleveland.D.W., 2007. Aneuploidy acts both oncogenically and as a tumor suppressor. Cancer Cell. 11, 25-36.

Wickham, H., 2009. ggplot2: Elegant Graphics for Data Analysis. Springer-Verlag New York. 


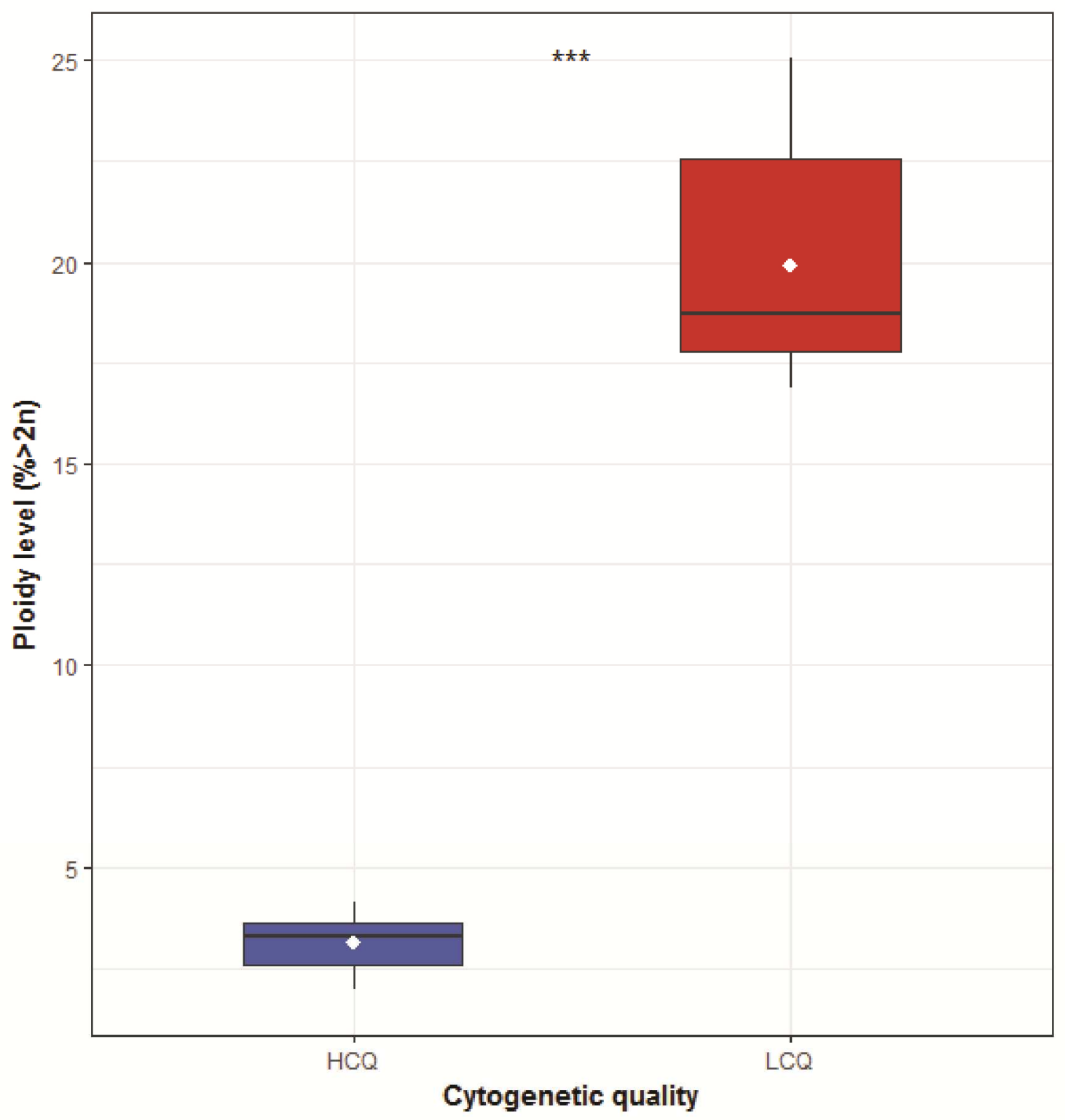

460

Figure 1: Variation of the non-diploid nuclei percentages within and between the two mussel stocks according to cytogenetic quality. boxplot). The upper, central and lower horizontal bars of the boxes indicate the 3rd quartile, median and 1st quartile, respectively. Upper and lower extremities of the whiskers represent the minimum and maximum values for each variable. Filled white diamonds correspond to mean values. Asterisks display significant differences between HCQ and LCQ ('***' $\mathrm{p}<$ 0.001 after tests of Wilcoxon). 


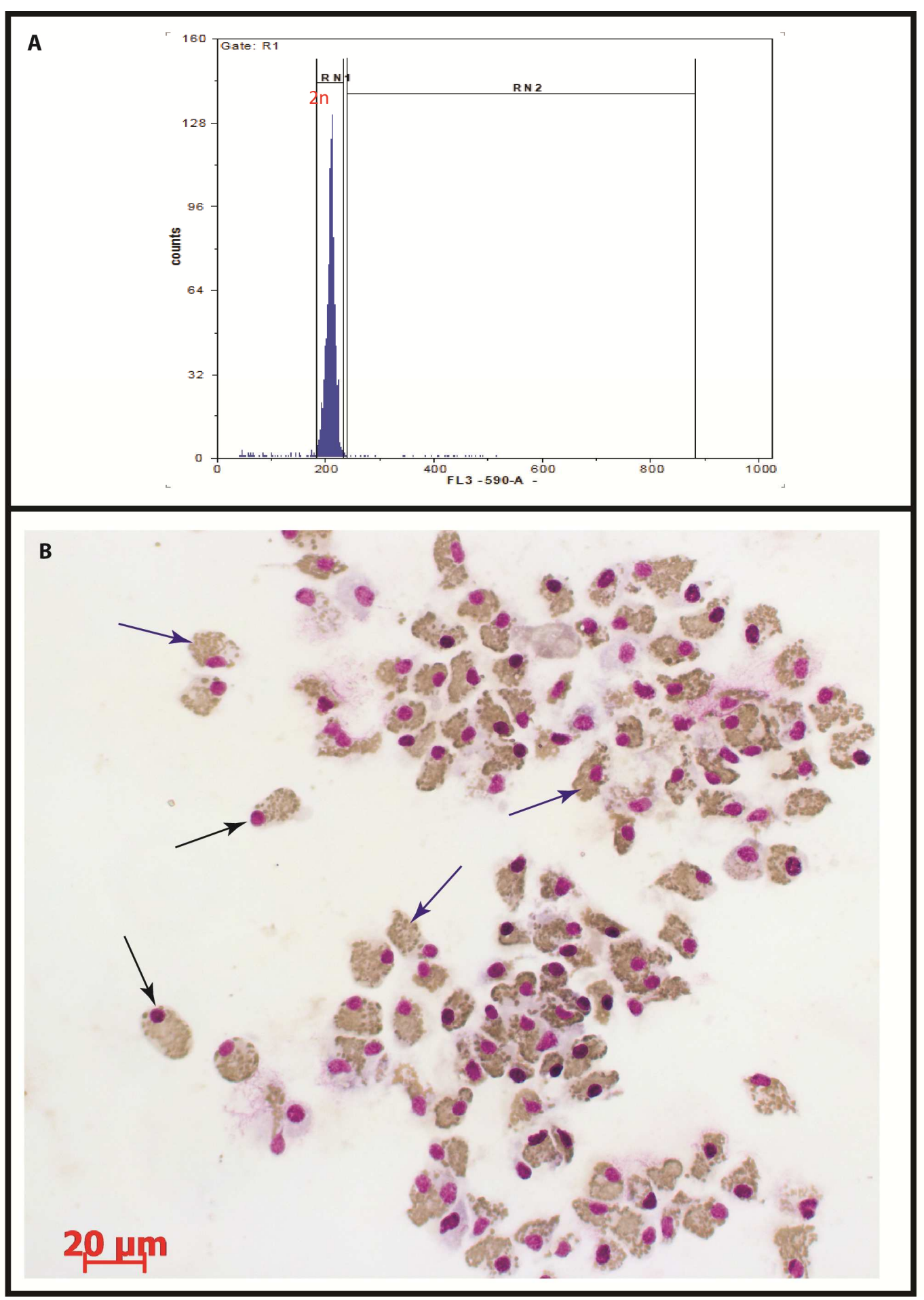

Figure 2: Flow cytometry and hemocytology analysis of HCQ blue mussels.

(A) Flow cytometry histogram of propidium iodide stained hemolymph nuclei from normal HCQ blue mussels. Histogram of propidium iodide fluorescence of gated single nuclei show Markers RN1 and RN2 placed to estimate the percentage of nuclei in diploid (2n) and nondiploid phases, respectively. (B) Hemolymph cell-monolayer preparation showing a large majority of normal granulocytes with nucleus stained dark purple (black arrows) and cytoplasm light purple (blue arrows). 


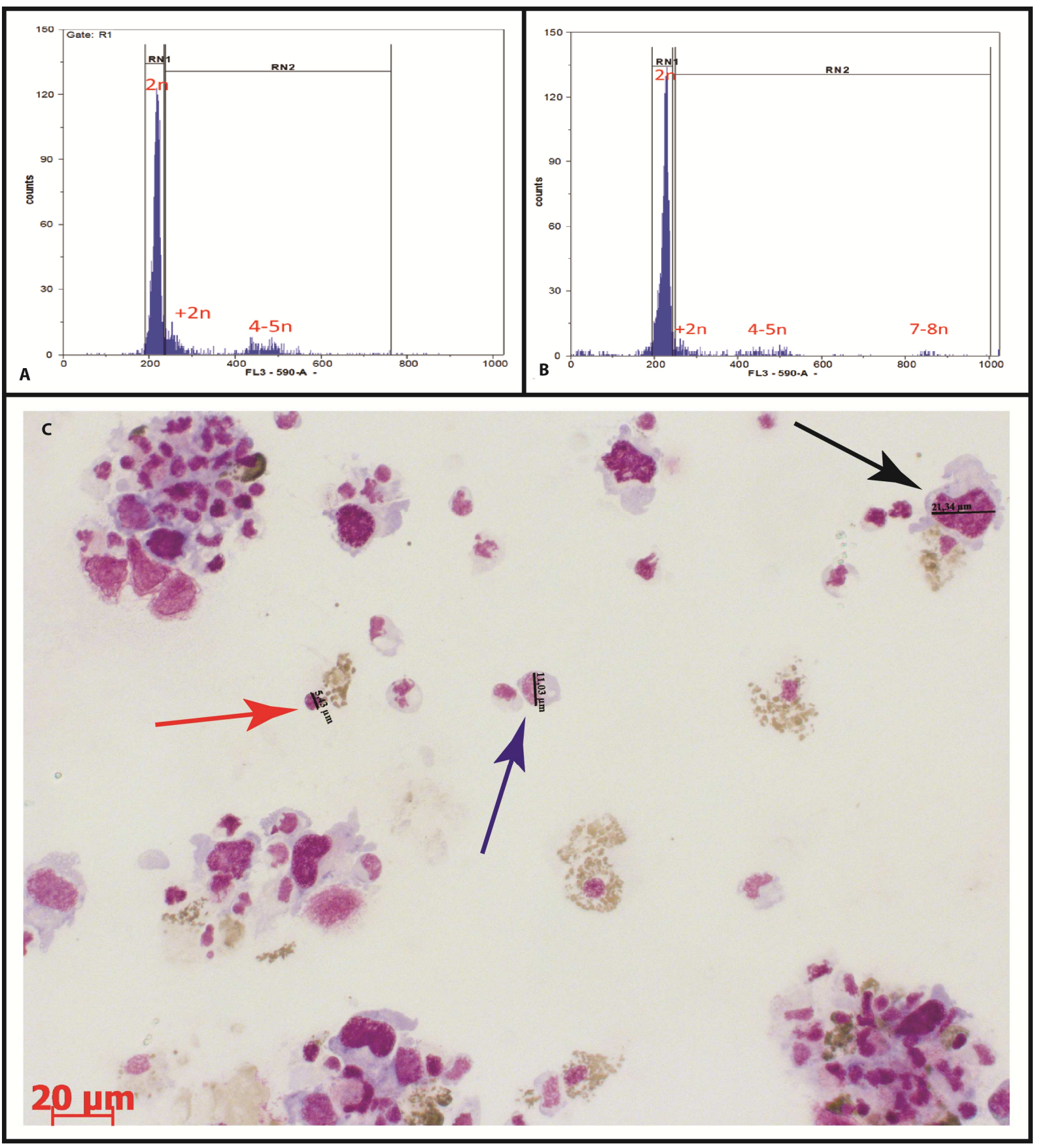

Figure 3: Flow cytometry and hemocytology analysis of LCQ blue mussel.

(A) and (B) Flow cytometry histograms of propidium iodide stained hemolymph nuclei from abnormal blue mussels. Histogram of propidium iodide fluorescence of gated single nuclei with markers RN1 and RN2 placed to estimate the percentage of nuclei in diploid (2n) and non-diploid phases. (A-B), Non-diploid nuclei included hyperdiploid-hypotriploid (2-3 n) to tetraploid-pentaploid (4-5 n) nuclei and (B) heptaploid-octoploidnuclei (7-8 n). (C) hemolymph cell-monolayer preparation showing few normal granulocytes with nucleus of normal mean size (5-6 $\mu \mathrm{m}$ of diameter, red arrow) and a majority of abnormal neoplastic cells that are rounded in shape with a reduced, granulation-free cytoplasm enclosing large (11-12 $\mu \mathrm{m}$, blue arrow) to very large nuclei (up to $20 \mu \mathrm{m}$, black arrow). 


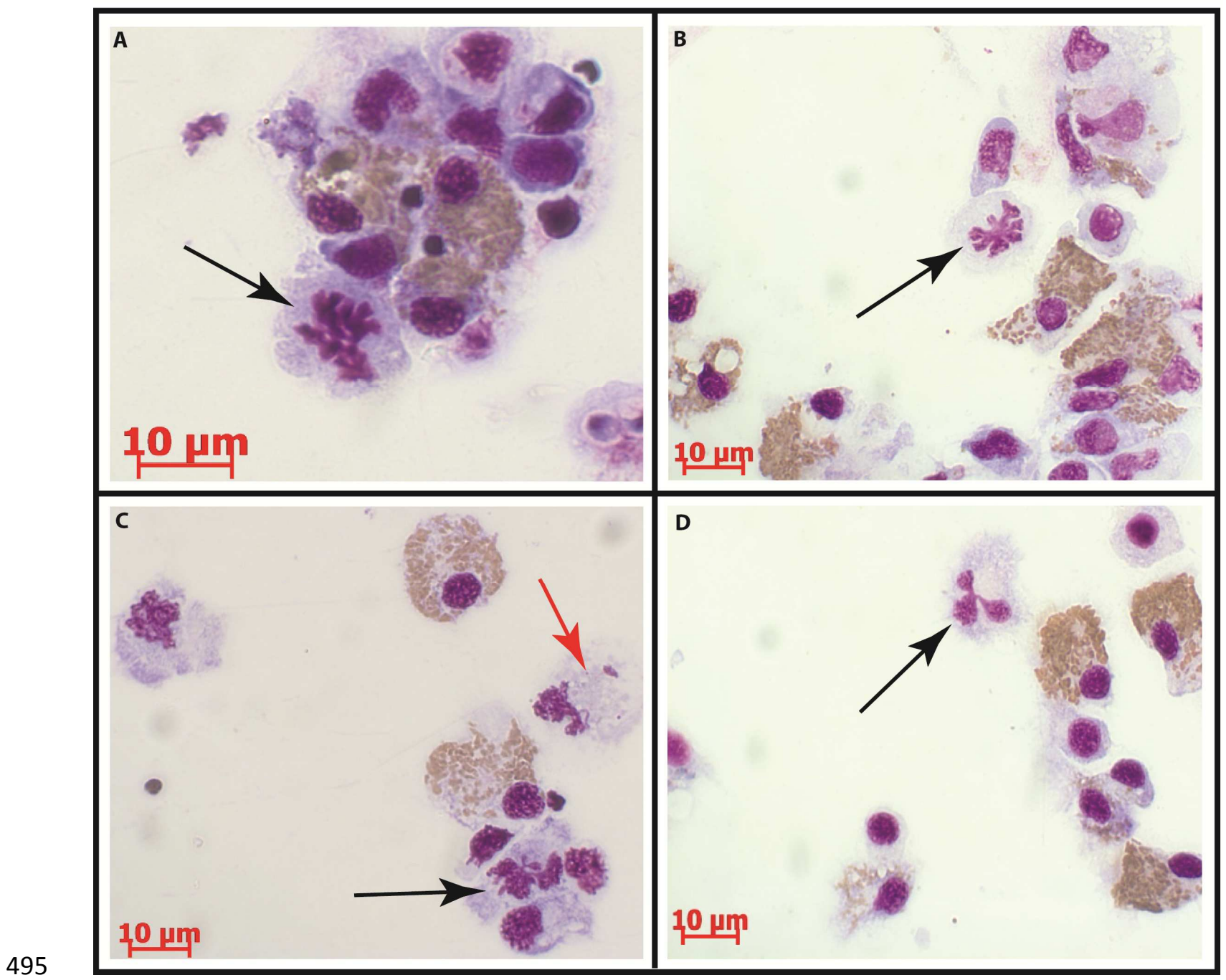

Figure 4: Hemocytology analysis of LCQ mussels with abnormal mitotic figures.

Black arrows indicate mitotic figures with abnormal segregation pattern including, star-like (B), unequal (A, C) and tripolar (D) segregation. (C) Red arrow indicates an unequal segregation pattern with lagging chromosomes. 


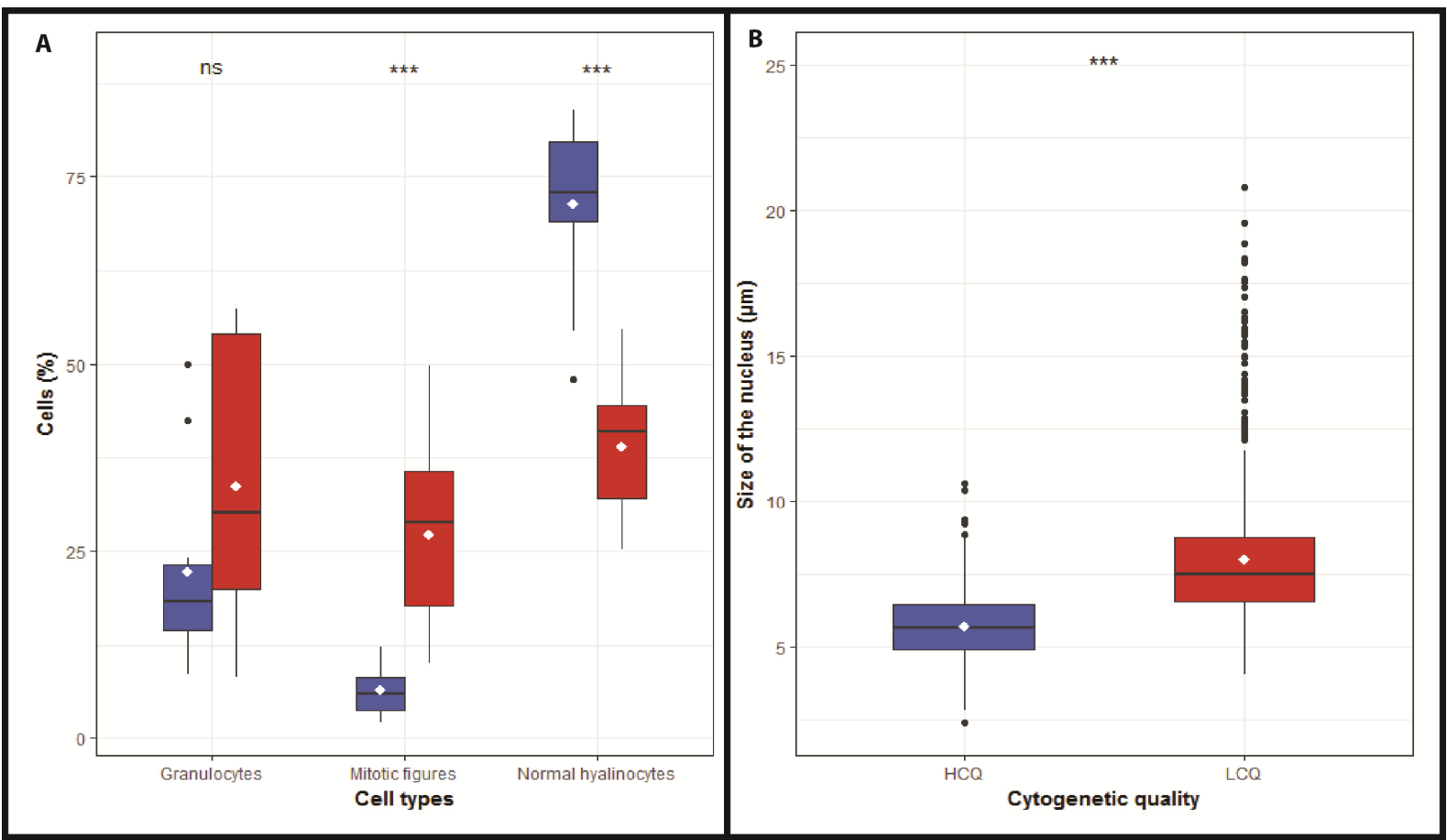

Figure 5: Analysis of cell characteristics from each mussel group LCQ and HCQ.

(A) Number of cells by cell types and (B) Nuclei sizes for HCQ and LCQ quality. HCQ: High Cytogenetic Quality (blue boxplot), LCQ: Low Cytogenetic Quality (red boxplot). The upper, central and lower horizontal bars of the boxes indicate the 3rd quartile, median and $1 \mathrm{st}$ quartile, respectively. Upper and lower extremities of the whiskers represent the minimum and maximum values for each variable. Filled white diamonds correspond to mean values. Asterisks display significant differences between HCQ ('***' $\mathrm{p}<0.001$ after tests of Wilcoxon) vs LCQ ('ns': non significance, $\mathrm{p}>0.05$ ). 